\title{
Parasitoid Species Associated with Immature Stages pieris rapae (L.) Inhabiting Cabbage Plantations in Assiut Governorate, Upper Egypt
}

\author{
Farouk Abdel-kawi Abdel-Galil ${ }^{1}$, Safaa Mohamed Abdel-Rahman Mohamed Amro ${ }^{2}$, \\ Abd El-Raheem Ahmed Abd El-Raheem ${ }^{2}$, Dalya Yousef Awad Darwish ${ }^{1}$, \\ Mervat Ahmed Badawy Mahmoud, *
}

${ }^{1}$ Plant Protection Department, Faculty of Agriculture, Assiut University, Assiut, Egypt

${ }^{2}$ Plant Protection Research Institute, Agricultural Research Centre, Dokki, Giza, Egypt

${ }^{3}$ Zoology Department, Faculty of Science, South Valley University, Qena, Egypt

\section{Email address:}

faagalil@hotmail.com (F. Abdel-kawi Abdel-Galil), faagalil@aun.edu.eg (F. Abdel-kawi Abdel-Galil), moamro1953@yahoo.com (S. M. Abdel-Rahman M. Amro), arhim67@gmail.com (A. El-Raheem A. A. El-Raheem), dalia.darwish@agr.au.edu.eg (D. Y. A. Darwish), mervat.mahmoud@sci.svu.edu.eg (M. A. B. Mahmoud) ${ }^{*}$ Corresponding author

\section{To cite this article:}

Farouk Abdel-kawi Abdel-Galil, Safaa Mohamed Abdel-Rahman Mohamed Amro, Abd El-Raheem Ahmed Abd El-Raheem, Dalya Yousef Awad Darwish, Mervat Ahmed Badawy Mahmoud. Parasitoid Species Associated with Immature Stages pieris rapae (L.) Inhabiting Cabbage Plantations in Assiut Governorate, Upper Egypt. American Journal of Entomology. Vol. 5, No. 2, 2021, pp. $27-31$.

doi: 10.11648/j.aje.20210502.12

Received: April 23, 2021; Accepted: May 17, 2021; Published: May 31, 2021

\begin{abstract}
This work was initiated for the first time to identify parasitoid species associated with the immature stages of Pieris rapae (L.) inhabiting cabbage plantations in Assiut governorate, Upper Egypt during the 2018 and 2019 cabbage growing seasons. Attacking periods and parasitism percentages (PPs) of the identified parasitoid species were calculated. One solitary parasitoid species, Hyposoter ebeninus was found to attack P. rapae larvae in the field 110 days after transplantation. However, one hyperparasitoid species Baryscapus galactopus was recorded as an internal gregarious hyperparasitoid of $H$. ebeninus. The solitary larval parasitoid H. ebeninus strikes were recorded throughout the last five weeks of the season with a marked decline before harvesting. Although H. ebeninus revealed $42.00 \%$ abundance, it presented $21.69 \%$ PP on $P$. rapae larvae during the entire period of study. One solitary, Brachymeria femorata and two gregarious parasitoid species [Pteromalus puparum (L) and Tetrastichus sp. (Haliday) were recorded as P. rapae pupae parasitoids on October, $2^{\text {nd }}$. Parasitism peak was recorded on October, $16^{\text {th }}$ with an average of $56.25 \%$. The first appearance of the gregarious pupal parasitoid $P$. puparum was recorded on October, $9^{\text {th }}$. Four weeks later, the second gregarious parasitoid (Tetrastichus sp.) was recorded on November, $6^{\text {th }}$. Both pupal gregarious parasitoid species were found to be active until harvesting. The gregarious parasitoid $P$. puparum presented high PP (23.73\%) as compared with Tetrastichus sp. which exhibited $6.96 \%$ PP during the entire period of study. In conclusion, two solitaries, one hyperparasitoid, and two gregarious parasitoid species were identified. Pupal gregarious parasitoid species together reduced $P$. rapae pupae populations by $30.69 \%$. These parasitoids could be used in the IPM programs for this pest in the future. At the same time, the effect of hyperparsitoides must be taken into consideration.
\end{abstract}

Keywords: Parasitoids Complex, Pieris Rapae, Parasitism Percentages, Abundance

\section{Introduction}

The white butterfly (WB), Pieris rapae (Linnaeus, 1758) (Lepidoptera: Pieridae) occurs in temperate regions around the world. WB larvae feeding habits caused ragged holes in the leaves of the host plant. Under heavy attack, only the veins are left, resulting in considerable losses to commercial growers. Less heavily infested plants become stunted and fouled with dark green pellets [1]. In Egypt, cabbage 
plantations have been subjected to attack by sever key insect pests e.g. the WB $P$. rapae [2].

Parasitoid species of $P$. rapae in northern Egypt were surveyed by Kolaib et al. [3]. The recorded parasitoids were the gregarious larval parasitoid, Apantelus glorneratus L., (Hymenoptera: Braconidae), the solitary pupal parasitoid, Brachyrneria femorata Panz. (Hymenoptera: Chalicididae) and the gregarious pupal parasitoid, Pteromalus puparum L. (Hymenoptera: Pteromalidae). In a field study in Kafr ElSheikh Egypt, Awadalla et al. [4] reported that $P$. rapae attacking cabbage plants was subjected to attack by the pupal parasitoids B. femorata and P. puparum. Also, El-Husseini et al. [5] found five parasitoid species associated with P. rapae when surveyed cabbage plantation in old cropland middle Egypt. The five recorded species were Trichogramma buesi V., Cotesia glomerata (L.), Hyposoter ebeninus Grav., Brachymeria femorata Panz, and Pteromalus puparum L.

Pesticide massive application and appearance of pest resistance strains, outbreaks of secondary pest, the absence or ineffective presence of natural enemies, and global worming and climate change are all contributing to changes in insect pest problems faced by farmers in Egypt's newly reclaimed land as well as in the old valley [6]. Recording natural biological control agents for plants is becoming increasingly important in order to expand our knowledge. The main objective of this manuscript is to identify parasitoid species attacking $P$. rapae immature stages (larvae and pupae) inhabiting cabbage plantations in the reclaimed areas in Assiut, Upper Egypt. Parasitism percentages and attacking duration were also taken into consideration.

\section{Materials and Methods}

\subsection{Experimental Design}

Experiments were conducted at a reclaimed area at the border of the eastern desert of Assiut governorate (private farm at El-Fath province) during the 2018 and 2019 cabbage growing seasons. Area of about $1050 \mathrm{~m}^{2}$ divided into plots $\left(10.50 \mathrm{~m}^{2} /\right.$ plot $)$. Cabbage seeds were planted in the greenhouse on $17^{\text {th }}$ June during both seasons. One month later cabbage seedlings were transplanted at a $50 \mathrm{~cm}$ distance at the sustainable farm. Regular agricultural practices were used. Chemical treatments were completely prevented.

The natural parasitism rates on $P$. rapae larvae were estimated weekly in the field by counting parasitized and non-parasitized larvae/plant (4 plants/ plot). However, parasitism rates on $P$. rapae pupae were estimate

$\mathrm{d}$ weekly by picking up $P$. rapae pupae inhabiting the outer and/or the middle leaves of randomly selected cabbage plants The collected larvae and pupae were transferred to the laboratory and kept individually in moistened test tubes (10 replicates) at the laboratory conditions $\left(22 \pm 3{ }^{\circ} \mathrm{C}\right.$ and $60 \pm 5$ R. H. \%). The test tubes were carefully labeled and covered with a piece of cotton to provide aeration. Emerged parasitoids were killed by chloroform and preserved at $-5^{\circ} \mathrm{C}$ in a freezer for later identification by the specialists in the biological control and taxonomy Departments in the Plant Protection Research Institute, Ministry of Agriculture.

Parasitism percentages (PP) on larvae and pupae were estimated by the equations used by Puneeth, \& Vijayan [7], Bhat [8] as follows:

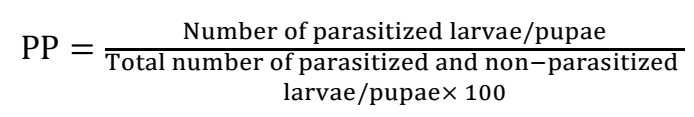

\subsection{Abbreviations}

$\mathrm{WB}=$ The White butterfly, $\mathrm{PPs}=$ Parasitism percentages, $H$. ebeninus=Hyposoter ebeninus, $P$. rapae=Pieris rapae, $B$. galactopus=Baryscapus galactopus, B. femorata=Brachymeria femorata, $P$. puparum=Pteromalus puparum, $(\mathrm{SWB})=$ The small white butterfly, R. H.=Relative Humidity, $\mathrm{H}=$ Highest $\mathrm{L}=$ Lowest, IPM=Integrated Pest Management, $\mathrm{A} \%=$ Abundance $\%, \mathrm{GPP}=$ General Parasitism Percentage.

\section{Results}

\subsection{Larval Parasitoids}

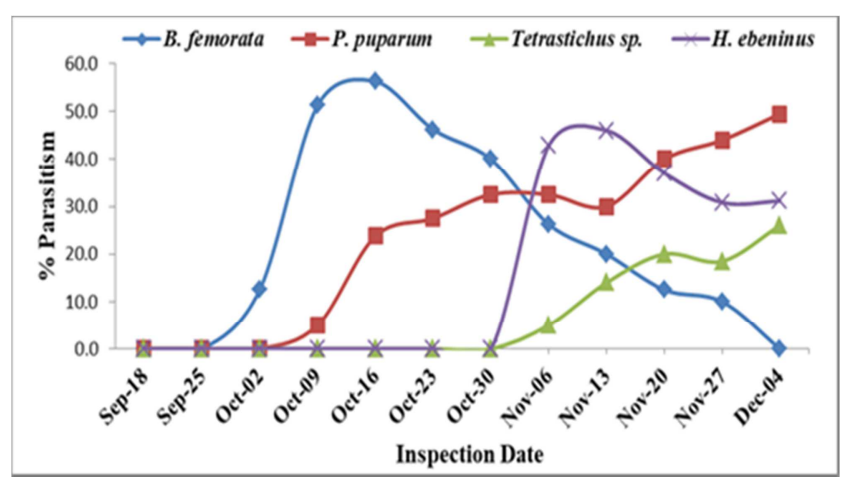

Figure 1. Mean parasitism percentages of the identified parasitoids attacking the cabbage white butterfly Pieris rapae larvae and pupae in cabbage fields in Assiut (El-Fath province) during 2018 and 2019 growing seasons.

One solitary parasitoid species, [Hyposoter ebeninus (Gravenhorst) (Hymenoptera: Ichneumonidae)] was recorded attacking $P$. rapae larvae in the field 110 days after transplantation. However, one hyperparasitoid species [Baryscapus galactopus (Ratzeburg) (Hymenoptera: Eulophidae)] was recorded as an internal gregarious hyperparasitoid of $H$. ebeninus. Data illustrated in Figure 1 revealed that the larval parasitoid Hyposoter ebeninus (Gravenhorst, 1829) attacking $P$. rapae larvae in cabbage fields during 2018 and 2019 growing seasons, 110 days after transplantation. The first attack of $H$. ebeninus on $P$. rapae larvae recorded $42.81 \% \mathrm{PP}$ on November $6^{\text {th }}$. Although $H$. ebeninus showed its highest attack in mid-November, its parasitism percentages declined gradually. Although $H$. ebeninus revealed $42.00 \%$ abundance percentage, it presented $21.69 \%$ PP on $P$. rapae larvae throughout the entire period of study (Table 1). Data collected during this investigation can be helpful in future studies for devising pest 
management strategies, especially against the cabbage white butterfly P. rapae.

Table 1. Mean parasitism percentages and abundance of the parasitoids attacking Pieris rapae larvae and pupae in cabbage fields in Assiut (El-Fath province) during 2018 and 2019 growing seasons.

\begin{tabular}{|c|c|c|c|c|c|c|c|c|}
\hline \multirow{3}{*}{ Parasitoid species } & \multicolumn{6}{|c|}{ Mean parasitism percentage } & \multirow{3}{*}{$\mathbf{A} \%(\subset$} & \multirow{3}{*}{ GPP } \\
\hline & \multicolumn{2}{|c|}{2018} & \multicolumn{2}{|c|}{2019} & \multicolumn{2}{|c|}{ Mean (2018+2019) } & & \\
\hline & $\begin{array}{l}\mathbf{H} \\
\end{array}$ & $\mathbf{L}$ & $\mathbf{H}$ & $\mathbf{L}$ & $\mathbf{H}$ & $\mathbf{L}$ & & \\
\hline Hyposoter ebeninus (Gravenhorst, 1829) (Hyn & 48.56 & 30.56 & 43.93 & 29.03 & 46.25 & 29.80 & 42.00 & 21.69 \\
\hline Brachymeria femorata (Panzer, 1801) (Hymenoptera: Chalcididae) & 60.00 & 10.00 & 52.00 & 10.00 & 56.00 & 10.00 & 75.00 & 22.92 \\
\hline Pteromalus puparum (L, 1758) (Hymenoptera: Pteromalidae) & 43.00 & 22.00 & 56.00 & 10.00 & 49.50 & 16.00 & 75.00 & 23.73 \\
\hline Tetrastichus sp. (Haliday, 1844) (Hymenoptera: Eulophidae) & 37.00 & 15.00 & 15.00 & 10.00 & 26.00 & 12.50 & 42.00 & 6.96 \\
\hline
\end{tabular}

$\mathrm{H}=$ Highest, $\mathrm{L}=$ Lowes, $\mathrm{A} \%=$ Abundance \%, (C) Based on 12 samples, GPP=General Parasitism Percentage

\subsection{Pupae Parasitoids}

Data illustrated in Figure 1 revealed that the first appearance of the solitary parasitoid Brachyrneria femorata (Panzer, 1801) was recorded on October, $2^{\text {nd }}$ (75 days after transplantation) with an average of $12.50 \%$ PP. Two weeks later PP of B. femorata multiplied and showed $51.25 \%$. The highest PP (peak) of $B$. femorata on $P$. rapae pupae was recorded on October $16^{\text {th }}$ with an average of $56.25 \%$. A gradual decrease in $B$. femorata PPs was recorded. The general PP of $B$. femorata during the entire period of the study recorded $22.92 \%$ (Table 1 ). On the other hand, $B$. femorata showed the highest abundance percentage (75.00\%) and the absolutely highest PPs on $P$. rapae pupae (56.00\%).

Data illustrated in Figure 1 revealed that two gregarious parasitoid species were recorded as parasitoids of $P$. rapae pupae in cabbage fields, vs. Pteromalus puparum (L., 1758) and Tetrastichus sp. (Haliday, 1844). The first appearance of $P$. puparum was recorded 82 days after transplantation (October, $9^{\text {th }}$ ). Four weeks later, the second parasitoid, (Tetrastichus sp.) was recorded in cabbage fields (November, $\left.6^{\text {th }}\right)$. It is important to point herein that both gregarious parasitoid species was found to be active until harvesting. Data revealed that $P$. puparum ranked the first and presented the highest PPs with an average of $23.73 \%$ compared with Tetrastichus sp which exhibited 6.96\% PP during the entire period of study. Gregarious parasitoid species together reduced $P$. rapae pupae populations by $30.69 \%$ (Table 1 ). Concerning the gregarious parasitoids parasitism and abundance percentages, data presented in Table 1 showed that $P$. puparum ranked the first and parasitized $P$. rapae pupae by the highest PP (ranged between 49.50 and $16.00 \%$ ). This parasitoid abundance percentage $(75.00 \%)$ was found to be equal to 1.71 fold of that presented by the second gregarious parasitoid (Tetrastichus sp.). Although, Tetrastichus sp. presented throughout 5 weeks only in the field, its PP (ranged between 26.00 and 12.50\%). This finding reflects the importance of this pupal parasitoid as an effective biological control agent against (WB) in cabbage fields.

\section{Discussion}

The present study was conducted for the first time in this area of northern Egypt. Results demonstrated the finding of just one solitary $p$. rapea larval parasitoid $H$. ebeninus and one hyperparasitoid $B$ galactopus. These results of the current investigations are in agreement with those obtained by the earliest, Abbas and Hassanein (1989) [9] who recorded the absolutely first parasitism in Egypt on P. rapae larvae in cabbage fields. Also, Deen \& Bhagat [10] found three parasitoids, C. glomerata, $H$. ebeninus and B. femorata from larvae and pupae of $P$. rapae as a first parasitism of this pest in India. Notable gradual decline of $H$. ebeninus abundance through the time, this finding could be attributed to the appearance of its eolophid hyperparasioid B. galactopus which appeared at the same period. Results of Settele et al. [11] confirmed the complementary need for parasitoid based knowledge. Their article explained that parasitoid complexes are not closed systems, and there is no a prior way of assessing whether a parasitoid reared from a particular species also uses related hosts, or perhaps unrelated ones occurring in similar environments. Therefore, researchers need to establish comprehensive knowledge not only of which species attack butterflies, but also of the host associations of each one. This is gradually accruing, at least for common parasitoid species, especially through smallscale rearing's involving a large number of host species.

Results further exhibited documentation of three parasitoid species conjugated with $P$. rapea paupae; One solitary, [Brachymeria femorata (Panzer) (Hymenoptera: Chalicididae)] and two gregarious parasitoid species [Pteromalus puparum (L) (Hymenoptera: Pteromalidae) and Tetrastichus sp. (Haliday) (Hymenoptera: Eulophidae)]. North Egypt, parasitoid species of $P$. rapae were surveyed by [3] during the two successive years of 2006 and 2007. The recorded parasitoids were the gregarious larval parasitoid, Apantelus glorneratus L.; the solitary pupal parasitoid, B. femorata and the gregarious pupal parasitoid, Pteromalus puparum L. Total parasitism percentages ranged between $5.70-16.20,7.80-20.00$ and $10.00-23.00 \%$ for A. glomeratus, B. femorata and $P$. puparum, respectively. In the same approach, Bhat \& Bhagat [12] reported that the solitary pupal parasitoid B. femorata was considered to be one of the most abundant parasitoids causing the highest extent of $18.5 \%$ parasitism on $P$. rapae pupae. They considered their finding as to the first report on $P$. rapae parasitism in India.

In a comparison between cruciferous host plants, Awadalla et al. [4] reported that cabbage plants harbored the highest average percentage of $P$. puparum during 2011/12 and 
2012/13 seasons and represented by 30.8 and $31.5 \%$ followed by cauliflower plants 24.4 and $26.6 \%$ while, canola plants recorded the last category and represented by $19.6 \%$ and $14.7 \%$, respectively. Five primary parasitoids vs. (Trichogramma buesi Voegel; Hyposoter sp.; Cotesia glomerata (L); Pteromalus puparum and Brachymeria femorata (Panzer) were found to associated with developmental stages of pieries rapea in field study conducted by El-Fakharany \& Hendawy [13].

On the other hand, several investigators proved that Tetrastichus species took an important role to manage pupae of some lepidopteran insect pests e.g. Baitha et al. [14] on the spotted stalk borer, Chilo partellus (Swinhoe) (Lepidoptera: Crambidae); Baitha \& Sinha [15] on the gold-fringed rice stem borer Chilo auricillius Dudgeon; [16-18] on the sugarcane borer Diatraea saccharalis (Fabr.) (Lepidoptera: Crambidae); [19] on Diatraea sp. and [20] on the ello sphinx Erinnyis ello (Linnaeus) (Lepidoptera: Sphingidae).

These parasitoid species could be efficient in the IPM field. In this approach, [21] results revealed that, Tetrastichus howardi parasitized on the larvae, pupae and adults of the sugarcane borer $D$. saccharalis, and therefore seems to be a suitable candidate for the biological control of this insect pest in commercial sugarcane. Parasitism and the emergence of $T$. howardi from the fifth instar larvae, pupae and adults of $D$. saccharalis revealed the ability of this natural enemy to establish itself in culture, even in the absence of host pupae.

\section{Conclusion}

Results showed that no egg parasitoid species were recorded, but for larvae, one solitary parasitoid species, $H$. ebeninus and one hyperparasitoid species $B$. galactopus was recorded as an internal gregarious hyperparasitoid of $H$. ebeninus. Regarding the pupae parasitoids, one solitary $B$. femorata and two gregarious parasitoid species $P$. puparum and Tetrastichus sp. were recorded. These results are important and could be used for the control of the pest in IPM programs in the future.

\section{Acknowledgements}

The authors were grateful to Prof. Dr. Magdy M Salem, Taxonomy Department and Prof. Dr. Ahmed S Hendawy, Biological Control Research Department, Plant Protection Research Institute, ARS, for identification arthropod species, parasitoid and hyperparasitoid species collected during this work. We would like to show our gratitude to Prof. Dr. Mohammed A. Amro, Plant Protection Research Institute, Agricultural Research Center, Dokki, Giza, Egypt, for his valuable and helpful comments reviewing an early version of this article. Special thanks to the staff members of Plant Protection Department, Faculty of Agriculture, Assiut University and staff members of Insect Research Laboratory in Assiut, Plant Protection Research Institute for supporting and encouragement during the study.

\section{References}

[1] Capinera, J. L. (2014). Imported Cabbageworm, Pieris rapae (Linnaeus) (Insecta: Lepidoptera: Pieridae). http://entomology.ifas. ufl. edu/creatures.

[2] Embaby, M. E., \& Lotfy, D. E. (2015). Control of the cabbage white butterfly (Pieris rapae L.) (Lepidoptera: Pieridae) using entomopathogenic fungi. Egyptian Journal Biological Pest Control; 25 (3): 569-572.

[3] Kolaib, M. O., Attia, M. B., Abd El-Naby, L. M., \& EIMadboh, W. F. (2009). On the parasitoids species of the cabbage worm, Artogeia (Pieris) rapae L. (Lepidoptera: Pieridae) at El-Minoufia Governorate, Egypt. Egyptian Journal Biological Pest Control; 19 (1): 63-66.

[4] Awadalla, S. S., EL-Serafi, H. A., Abdel - Samad, S., \& Abdou, A. K. (2013). The seasonal activity of the main insect parasitoids attacking pupal stage of the cabbage butterfly Pieris rapae L. on different host plants. Journal of Plant Protection and Pathology; 4 (8): 693-699.

[5] El-Husseini, M. M., El-Heneidy, A. H., \& Awadallah, K. T. (2018). Natural enemies associated with some economic pests in Egyptian agro-ecosystems. Egyptian Journal Biological Pest Control; 28: 78-17.

[6] Ibrahim, H. M. (2020). Seasonal Fluctuations of the Cabbage White Butterfly, Pieris rapae (L.) and its Natural Enemies on Cabbage in Middle Egypt. Middle East Journal of Applied Sciences; 10 (4): 693-697.

[7] Puneeth, P., \& Vijayan, V. A. (2014). Parasitization capacity of Trichogramma chilonis ishii (Hymenoptera: Trichogrammatidac) on the eggs of Helicoverpa armigera (Lepidoptera: Noctuidae) under laboratory conditions. International Journal of Science Nature; 5 (3): 462-465.

[8] Bhat, D. M. (2018). Incidence and diversity of lepidopterous insect pests and their parasitoids (natural enemies) on Cole crops at danderkhah location in Srinagar District ( $\mathrm{J} \& \mathrm{~K}$, India). International Journal of Entomology Research; 3 (2): 107-113.

[9] Abbas, M. S. T., Hassanein, F. A. (1989). First record of Hyposoter ebeninus Grav. in Egypt parasitizing Pieris rapae L. larvae in cabbage fields. International Conference of Economic Entomology, Cairo Egypt, December 11-14, pp 57-63.

[10] Deen, M. B., \& Bhagat, R. C. (2009). Natural parasitism of Pieris rapae (L.) and Pontia daplidice (L) (Lepidoptera: Pieridae) on cruciferous crops in Kashmir Valley (India). American Eurasian Journal of Agriculture Environmental Science; 5 (4): 590-591.

[11] Settele, J. Shreeve, T., Konviýka, M., \& Van Dyck, H. (2009). Ecology of Butterflies in Europe (C) Cambridge University Press, pp. 130-156.

[12] Bhat, D. M., \& Bhagat, R. C. (2009). Natural parasitism of Pieris rapae (L.) And Pontia daplidice (L.) (Lepidoptera: Pieridae) on cruciferous crops in Kashmir Valley (India). American-Eurasian Journal of Agriculture and Environmental Science; 5 (4): 590-591.

[13] El-Fakharany, S. K. M. \& Hendawy A. S. (2014). Field studies on cabbage white butterfly, Pieris rapae (Linnaeus) and its associated parasitoid and predatory species in Egypt. Egyptian Journal Biological Pest Control, 24 (2): 437-444. 
[14] Baitha, A., Jalali, S. K., Rabindra, R. J. \& Venkatesan T (2004). Parasitizing efficiency of the pupal parasitoid, Tetrastichus howardi (Olliff) (Hymenoptera: Eulophidae) on Chilo partellus (Swinhoe) at different exposure periods. Journal of Biological Control; 18: 65-68.

[15] Baitha, A., \& Sinha, O. K. (2005). Intrinsic rate of natural increase of Tetrastichus howardi on Chilo auricillius. Annals of Plant Protection Sciences, 13 (2): 468-70.

[16] Gonzalez, J. F. A., Oca, F. N. M., \& Ravelo, H. G. (2003). Bio-ecological studies of Tetrastichus howardi Olliff. (Hymenoptera: Eulophidae), pupal parasite of Diatraea saccharalis (Fabr) (Lepidoptera: Crambidae) in Cuba. Centro Agricola 30: 37-41.

[17] Cruz, I., Redoan, A. C., Silva, R. B., Figueiredo, M. L., \& Penteado - Dias, A. M. (2011) New record of Tetrastichus howardi (Olliff) as parasitoid of Diatraea saccharalis (Fabr.) on maize. Scientia Agricola; 68 (2): 252-54.

[18] Costa, D. P., Pereira, F. F., Kassab. S. O., Rossoni, C., Favero
K., \& Barbosa, R. H. (2014). Playing Tetrastichus howardi in pupae of Diatraea saccharalis of different ages. Amazonian Journal of Agricultural and Environmental Science; 57: 67-7.

[19] Vargas, E. L., Pereira, F. F., Tavares, M. T., \& Pastori, P. L., (2011). Record of Tetrastichus howardi (Hymenoptera: Eulophidae) parasitizing Diatraea sp. (Lepidoptera: Crambidae) in sugarcane crop in Brazil. Entomotropica; 26: 135-138.

[20] Barbosa, R. H., Kassab, S. O., Pereira, F. F., Rossoni, C., Costa, D. P., \& Berndt, M. A. (2015). Parasitism and biological aspects of Tetrastichus howardi (Hymenoptera: Eulophidae) on Erinnyis ello (Lepidoptera: Sphingidae) pupae. Ciência Rural; 45 (2): 185-188.

[21] Pereira, F. F., Kassab, S. O., Calado, F. V. R., Vargas, E. L., Oliveira, H. N., \& Zanuncio, J. C. (2015). Parasitism and emergence of Tetrastichus howardi (Hymenoptera: Eulophidae) on Diatraea saccharalis (Lepidoptera: Crambidae) larvae, pupae and adults. Florida Entomological; 98 (1): 377-380. 